\title{
Construcción del sentido y mediación traductiva: el caso de la preposición francesa chez
}

\author{
Meaning construction and translation: the case of French \\ preposition chez
}

\author{
Patricia Camen Hemández \\ Universidad de Buenos Aires, Argentina
}

\begin{abstract}
Resumen: Este artículo aborda la relación entre construcción del sentido y traducción en un caso específico: la traducción de la preposición francesa chez en Le Rouge et le Noir (Rojo y Negro) de Stendhal y seis de sus traducciones al español. Luego de una breve reseña del comportamiento semántico-pragmático de la preposición chez, nuestro estudio examina las diversas refomulaciones de prendre chez + moi / lui provistas por las versiones en español. Tal a nálisis cualitativo nos pemite caracterizar las variadas construcciones de una misma escena e ilumina particularmente la subjetividad del traductor.
\end{abstract}

Mots-clés : pa rá frasis, preposición, sentido, subjetividad, tra ducción fra ncés-español.

Abstract This paper deals with the relationship between meaning construction and translation in a specific case study: the translation of the French preposition chez in Stendhal's Le Rouge et le Noir (The Red and the Black) and six of its Spanish translations. After a brief summary of the semantic-pragmatic behavior of the preposition chez, this study examines the diverse reformulations of prendre chez + moi / lui provided by the Spanish versions. This qualitative analysis allows us to characterize the various construals of the same scene and underlines the translator's subjectivity.

Keywords: paraphrase, preposition, mea ning, subjectivity, French-Spa nish translation.

\section{Introduc ción}

En este artículo, proponemos un estudio cualitativo de la diversidad de reformulaciones suscitadas en español por el empleo de la preposición francesa chez.

Nuestra aproximación a la mediación traductiva se sustenta en una visión no composicional, gestaltista y fenomenológica de la construcción del sentido: como proceso dinámico entre formas semánticas en interacción con su entomo lingüístico, tal construcción es inseparable de la consciencia perceptiva del interpretante (Cadiot y Visetti, 2001). Planteamos por tanto una aprehensión enunciativa del proceso de mediación interlingüística como lugar de inscripción de la subjetividad del traductor.

Desde esta perspectiva, abordamos el caso de la traducción de la preposición francesa chez, relacionante sin homólogo estricto en español, y proponemos un 
análisis cualitativo de seis traducciones al español de dos ocurrencias de la expresión prendre chez + pronombre localizadas en Rojo y negro de Stendhal. La diversidad de reformulaciones identificadas en el corpus examinado constituye, sostenemos, en el observable lingüístico, la huella de la pluralidad de escenific aciones, necesariamente subjetivas, que emergen de la instancia simbólica de traducción.

Tras una breve presentación de nuestro enfoque teórico (apartado 1), resumimos la descripción del comportamiento semántico-pragmático de la preposición francesa según la literatura de especialidad así como sus traducciones más usuales (apartado 2). Luego, definimos nuestro corpus de estudio (apartado 3) para detenemos finalmente en el a nálisis de casos (aparta do 4) según dos tendencias en la escenificación traductiva: la alusión a una interacción pertinente y la imagen de intrusión en un espacio privado. Por último, brindamos las conclusiones provisionales de este estudio.

\section{Una aproximación a la construcc cón del sentido en traducción}

Nuestra investigación integra una visión dinámica y fenomenológica de la construcción del sentido desde un enfoque holístico que toma en cuenta la interacción entre las unidades lingüísticas co-presentes. Tal concepción permea asimismo nuestra aproximación a la mediación traductiva: en tanto paráfrasis interlingüística, concebimos la traducción como un proceso no unívoco. Desde esta perspectiva, abordaremos el comportamiento semántico-pragmático de la preposición francesa chez como evocación de un temitorio vectorizado hacia la entidad designada por el sintagma preposic ional y, estudiaremos partic ula mente la negociación de sentidos entre las fomas que integran la secuencia prendre chez + pronombre.

\subsection{La construcción del sentido como proceso dinámico y gestáltico}

Como proceso dinámic o holístico (Vic tomi y Fuchs, 1996), la construcción del sentido no se reduce al ensamblaje de elementos prefomateados, sino que es el resultado emergente de transacciones simultáneas y estabilizaciones transitorias entre unidades lingüísticas en contexto. Se trata pues de una negociación constante entre fomas semánticas en curso de construcción (Cadiot y Visetti, 2001) que abordamos aquí desde una perspectiva fenomenológica: en el proceso de estabilizaciones transitorias del sentido en construcción se difuminan diferencias entre el sujeto que percibe y el objeto percibido. En efecto, el sentido se constituye, en la consciencia individual, no por la adición composicional de significados inmanentes sino a partir de un conjunto de indicaciones que se perfilan de modo dinámico según las modalidades de presencia que se generan en el campo subjetivo del interpretante. El 'contenido' del texto no puede sustraerse, entonces, a su forma de apareceren la consciencia receptiva.

Así, en la mediación traductiva, la escenificación propuesta por el texto-fuente (TF) y co-construida en el recomido interpretativo del tra ductor, emerge y se da a ver en la puesta en palabras del texto-meta (TM) elaborado por este último. A este respecto, partimos de una visión enunciativa de la traducción como proceso no 
unívoco en el que la pluralidad de fomulaciones observables constituye la huella de las diferentes escenificaciones, necesariamente subjetivas, propuestas por el traductor según su criterio de equivalencia en un proceso de paráfrasis interlingüístic as que describimos en el siguiente a parta do.

\subsection{La mediación traductiva como fenómeno enunc iativo}

Desde el punto de vista enunciativo, la traducción se basa, pues, no en el reconocimiento de una identidad a priori entre fomulaciones pre-existentes sino en un proceso dinámico efectuado por un sujeto en situación. En el curso de la construcción textual, el traductor opera, según las características de ambas lenguas, una modulación de sentidos (sobre-deteminación o sub-deteminación, según los casos).

Siguiendo la caracterización del proceso de paráfrasis elaborada por Fuchs (1982: 125-166), postulamos que, en el proceso traductivo, intervienen diferentes reducciones: primeramente, la reducción de la distancia entre el propósito enunciativo y el semantismo producido por la puesta en palabras del TF en la lengua de partida (L1); en segundo lugar, la contracción de la brecha entre el semantismo del TF en L1 y la recepción del traductor, relegando niveles de lectura discordantes e interpretaciones no pertinentes. En su refomulación del TF en la lengua de llegada (L2), el traductor moviliza un conjunto de formulaciones posibles entre las cuales selecciona una que juzga como más próxima a su interpretación del TF, desechando las demás, según la escenific ación que surge en su consciencia perceptiva. Esta elección supone, por un lado, la reducción de la distancia entre el propósito enunciativo del traductor y su producción efectiva y, por otro lado, la anulación de la discrepancia entre $T F$ en $L 1$ y $T M$ en $L 2$ según su criterio de equivalencia.

El involucramiento subjetivo del traductor -'fuerzas deformantes inconscientes', según Beman (1985) - agrega a la traducción una dimensión enunciativa ineludible: en tanto mediador, el traductor deja traza de su individualidad por incremento o disminución -incrémentalisation o entropie en téminos de Ladmiral (1979: 19, 219) -. Dado que se trata de una modulación subjetiva entre dos sistemas particulares según el criterio de invariancia adoptado por cada traductor, la mediación interlingüística puede dar lugar a rupturas de relación de isomorfismo en virtud tanto de las particularidades de cada lengua-cultura como de interpretaciones emergentes de la percepción del TF. Nuestro estudio se centra rá en estas rupturas con continuidad de interpretación semántico-pragmática según la anulación de discordancias caracterizada por Fuchs (1982) para el proceso de refomulación parafrástica.

Por supuesto, cabe resaltar que tales modulaciones existen asimismo en el proceso interpretativo realizado por el lector. Son ellas las que, desactivando divergencias, contribuyen a la ilusión de la transparencia y la homogeneidad del lenguaje con el corolario de la univocidad de la traducción, es decir, la creencia del 'hablante ingenuo' según la cual se pasa sin dificultad de una lengua a otra ya que se trata de dispositivos que codifican sin ambigüedades la realidad extra lingüístic $a$. 


\section{E comportamiento semántico-pragmático de la preposición chez}

En los apartados que siguen, abordamos brevemente el semantismo de la preposición francesa atendiendo tanto a su origen etimológico como a sus extensiones de sentido y empleos actuales ${ }^{1}$. Seguidamente, realizamos una breve descripción de las a proximaciones existentes en español para, finalmente, con un enfoque holístico, concentramosen la secuencia prendre chez + pronombre.

\subsection{La noción de temitorio propio}

Según el Nouveau Dictionnaire Etymologique de Dauzat et al. (1964), la preposición chez es una forma átona del francés antiguo chiese, del latín casa, término que, en latín clásico, designaba una cabaña o choza ${ }^{2}$. Etimológicamente, la preposición se encuentra ligada, entonces, a la idea de domicilio, residencia de un ser animado (nótese que chez introduce siempre un témmino ${ }^{3}$ animado $u$ objeto de personificación). El relacionante interviene asimismo en la formación del substantivo invariable chez-moi, chez-soi para indicar, con valor afectivo, el domic ilio personal. Se transparenta, en tal expresión, el estrecho vínculo de interioridad entre el sujeto y su morada. Se sentir chez soi, signific a sentirse en su propia casa, cualquiera sea el lugar que brinde resguardo para el propio yo, según una relación que se teje pemanentemente entre el sujeto y un entomo familiar delimitado en el que se establece la propia intimidad. Tal espacio, habitable y habitado -el acto fundador de 'habitar' constituye un movimiento de organización y de apropiación del espacio-, no es ajeno a la idea de pertenencia. En efecto, casa y habitación evocan pemanencia y también posesión: habitare ('ocupar un lugar') se relaciona con habeo ('tener, poseer') (Le Scouamec, 2007: 92). En este sentido, la ocupación de un lugar evoca tangencialmente la noción de posesión.

Es así como subyace en el empleo de la preposición francesa un matiz de propiedad. Los ejemplos (1)-(2), que tomamos de Charaudeau (1992: 428), ilustran la diferencia semántica entre las preposiciones chez y dans en téminos de pertenencia:

\footnotetext{
1 Si bien dic cionarios (por ejemplo el TLF) y gramáticas (Charaudeau, 1992, entre otros) caracterizan detalladamente los empleos de este relacionante, pocos estudios le son dedicados de modo particular. Por supuesto, es ineludible citar el capítulo que le dedica Pierre Cadiot en Les prépositions abstraites en français (1997) y el a nálisis posterior que publica en coautońa con Yves-Marie Visetti (2001). Son estos dos estudios partic ula res los que inspiran el presente a nálisis. Otros trabajos abordan deteminados aspectos de los empleos de dicho relacionante, tal el caso de Condamines (2000) que observa el empleo de chez en la indic ación de relación parte-todo en un compus de textos de ciencias naturales ('chez les primates, la mandibule a des mouvements verticaux') y Schnedecker (2007) que estudia la construc ción Adj + de chez + adj. ('un ciel gris de chez gris'). Con respecto a la traducción de la preposición, puede mencionarse una investigación sobre la expresión de los valores de chez en laslenguas afric anas (Adekpate, 2012).

2 Según Gougenheim (1972 [1952]: 172), el témino fue desplazado por maison (del latín mansio, posta, dejando como única huella la foma chaise en el nombre de la abadía la Chaise-Dieu (la Casa de Dios), forma que no debe confundirse con el término actual chaise (silla), alteración de chaire, deriva do del latín cathedra.

3 Se designa como témino de la preposición el complemento situado a la derecha del relacionante, frecuentemente un grupo nominal ('chez une copine') o un pronombre ('chez moi') (RAE y Asociación de Academias de la Lengua Española, 2009).
} 
(1) Viens dans la maison que j'ai louée pour un mois [Ven a la casa que he a lquila do por un mes]

(2) Viens chez moi [Ven a (mi) casa]

En (1), el hablante evoca un espacio con una visión funcional sin correlato de propiedad mientras que, en (2), el espacio designado (aún siendo alquilado) a parece como un teritorio propio. Portal motivo, el ejemplo de Cadiot (1997: 188):

(3) Viens chez moi, j'habite chez une copine [Ven a (mi) casa, vivo en casa de una a miga ]

no es necesariamente contradic torio ya que, en (3), el locutor siente (y escenifica) el lugar como propio. El sentido básico de chez se encuentra pues ligado a la construcción de un espacio de intimidad que, en la realidad extralingüística, identifica un lugar que el locutor designa como su residencia independientemente de toda restric ción temporal (Ca diot 1997: 187).

El origen 'doméstico' de chez, vinculado al espacio de intimidad inherente a la noción de casa, que remite, en español, tanto a la morada como a la familia y la descendencia ${ }^{4}$, sustenta la noción de interioridad que caracteriza los empleos comientes de la preposic ión. Tales empleos se extienden, como señala Cadiot (1997) según un doble movimiento concéntrico que parte desde el témino preposicional (núcleo de este espacio real o virtual) hacia el entomo próximo (grupo de personas, país, especie) u orientado hacia el interior de este perímetro, la intimidad del ser humano, su carácter y sus obras como creación. En el primer caso, a partir de la residencia (chez mon oncle, 'en casa de mi tío') y del local profesional5 (chez le pharmacien, 'en la famacia'), se amplifican los valores de empleo para remitir a una comunidad (chez les étudiants, 'entre los estudiantes'), una especie (chez les chats, 'en los gatos') o abarcar la región, el país (chez les Espagnols, 'entre los españoles', 'en España'). Con una orientación interior, hacia el ser humano, el relacionante alude a la obra (chez Montaigne, 'en Montaigne') o a la personalidad (c'est une habitude chez lui, 'es una costumbre en él'). Chez establece así "zonas concéntricas" que pemiten múltiples estabilizaciones referenciales siempre marcadas por una zona de intimidad autocentrada (Cadiot, 1997: 188; Cadiot y Visetti, 2001: 39): domic ilio, negocio, comunidad, especie, país, obra, personalidad.

Puede decirse, entonces, que la preposición francesa localiza en términos de pertenencia y de intimidad, sin una configuración particular ni descripción del espacio considerado como propio: se trata de un relacionante a-descriptivo apto para evocar una interacción pertinente con el referente a nimado designado por el término de la preposición.

\footnotetext{
4 En francés, además del término maison, existe maisonnée, para referirse al conjunto de quienes habitan la misma casa.

5 Según Milner (1989) y Leeman (1989), el empleo de chez puede generar ambigüedades por la indistinción entre espacio doméstico y profesional. En tal sentido, Milner (1989: 76) señala que "Je vais chez le coiffeur" puede introducir tanto una interpretación social ("Je vais chez le coiffeur pour fêter Noël avec lui", 'voy a casa del peluquero para celebrar con él la Navidad') como una profesional ("Je vais chez le coiffeurme faire c ouper les cheveux", 'voy a la peluqueńa para cortame el pelo'). Nótese que en español la elección del lexema propio al lugar de ejercicio profesional permite orientar la interpretación.
} 


\subsection{Una variedad de aproximaciones posibles en español}

Sin equivalente estric to en español, el empleo del relacionante francés, supone, para la mediación traductiva, tanto la restitución del referente como la a proximación contextual a la relación instanciada porla preposición.

Con respecto a la restitución del referente implíc ito en el empleo preposicional, si bien con gran frecuencia se introduce el término casa -por ejemplo en (2)-(3) -, las designaciones cambian según variables contextuales: pueden aparecer téminos tales como departamento, habitación, etc. o incluso la expresión neutra a / en lo de. Los sintagmas preposicionales conformados por el lexema casa admiten construc ciones con y sin determinante (sintagma desnudo) del tipo 'ir a la casa de Pablo' vs 'ir a casa de Pablo' así como empleo de posesivos (ir a su casa). En contextos alusivos a una actividad profesional, aparecen vocablos específicos (peluquería, floreńa, etc.). Ciertos empleos dinámic os, en coocurrencia con el verbo ir, generan expresiones como ir a ver a X en base a la interacción pertinente inferida entre los actantes involucrados en la relación evocada por la preposición. En empleos de valor más extendido que la indicación domiciliaria, pueden surgir términos tales como tierra, país o la designación de un país en particular (chez les Belges $\approx$ en Bélgica). Con referencia temporal, la fo mulación 'chezles Anciens', por ejemplo, puede suscitar 'en la Antigüedad'.

En cuanto a la selección preposicional, la búsqueda de un equivalente pertinente supone una negociación de sentidos con el entomo lingüístico. La traducción de chez suele convocar a la preposición a, para empleos dinámicos (ir a (la) casa de Pablo), y en para empleos estativos (estar en (la) casa de Pablo). Sin embargo, preposiciones como ante, con, entre, y para, permiten instanciar relaciones próximas a aquellas evocadas por el relacionante francés. Las diversas posibilidades, presentadas aquí sin exhaustividad, ilustran un amplio abanico de formula ciones, por supuesto, dependientes de cada contexto.

(i) Chez $\rightarrow$ A / En (+determinante) + casa de +N

(4) II m'a téléphoné pour me dire qu'il passait la nuit chez Noëllie $\rightarrow \mathrm{Me}$ telefoneó para decime que pasaba la noche en casa de Noëllie (Beauvoir, 1967: 229; trad. de Dolores Sierra y Néstor Sánc hez, 1974: 240).

(5) Elle devait aller chez sa tante $\rightarrow$ Tenía que ir a casa de su tía (Camus, 1957 [1942]: 36; trad. de Bonifacio del Camil, 1949: 31).

(ii) Chez $\rightarrow$ A / En (+posesivo) + casa

(6) Je reste chez nous $\rightarrow$ Me quedo en casa (Beauvoir, 1967: 244; trad. de Dolores Sierra y Néstor Sánc hez, 1974: 255).

(7) En sortant, elle est venue chez moi $\rightarrow$ Al salir vino a mi casa (Camus, 1957 [1942]: 36; trad. de Bonifacio del Ca mil, 1949: 30).

(8) Mon grand-père hausse le ton: «Je voudra is bien voir qu'ils m' expulsent: je suis chez moi! $\rightarrow$ Mi abuelo alza el tono: “ ¡A ver si se atreven a expulsarme! ¡Estoy en mi casa!" (Sartre, 1964: 33; trad. de Manuel Lamana, 1964: 25). 
(iii) $\mathrm{Chez} \rightarrow \mathrm{A} /$ En lo de $+\mathrm{N}$

(9) Le 31 décembre nous réveillonnons chez Isabelle $\rightarrow$ El 31 de diciembre vamos a lo de Isabelle (Beauvoir, 1967: 217; trad. de Dolores Sierra y Néstor Sánchez, 1974: 228).

(10) Je la revois à ce dîner chez Diana $\rightarrow$ Vuelvo a verla en esa comida en lo de Diana (Beauvoir, 1967: 153; trad. de Dolores Sierra y Néstor Sánchez, 1974: 161).

(iv) Chez $\rightarrow \mathrm{A} / \mathrm{En}+\mathrm{N}$ (sitio espec ífic o va riable $\mathrm{H}$ o $-\mathrm{H}$ )

(11) Aller chez le dentiste $\rightarrow$ Ir al dentista (García Pelayo y Gross y Testas, 1967, artículo chez).

(12) II me poussa chez le coiffeur $\rightarrow$ Me metió en la peluquería (Sartre, 1964: 89 ; trad. de Manuel Lamana, 1964: 69).

(v) Chez $\rightarrow$ ir a ver $+\mathrm{N}$

(13) Un matin, il m'emmena chezle proviseur $\rightarrow$ Me llevó una mañana a ver al director (Sartre, 1964: 67; trad. de Manuel Lamana, 1964: 50).

(vi) Chez $\rightarrow$ En $+\mathrm{N}$ específic o variable $(+\mathrm{H}$ o $-\mathrm{H})$

(14) Elle achète ses chaussures chez Bailly $\rightarrow$ Ella se compra los zapatos en Bailly (Ca diot, 1997: 271).

(15) C'est chez moi une habitude $\rightarrow$ En mí es una costumbre (García Pelayo y Gross y Testas, 1967, a rtículo chez).

(16) Le regard infini que j'a pprécia is tout particulièrement chez Mme Pic a rd $\rightarrow$ La mirada infinita que apreciaba particularmente en la señora Picard (Sartre 1964: 88; trad. de Manuel Lamana, 1964: 66).

(17) Chez Proust, les phrases n'ont pas de fin $\rightarrow$ En Proust, las frases no teminan (Cadiot, 1997: 271).

(18) Chez les Anglais on boit du thé à n'importe quelle heure $\rightarrow$ En Inglaterra se toma té a cualquier hora / Los ingleses toman té a cualquier hora (Cadiot, 1997: 188).

(19) Chez les esquimaux, on se sert du renne pour tirer les traîneaux $\rightarrow$ En tiema de los esquimales, se utiliza el reno para tirar de los trineos (Bouzet, 1946: 143).

(20) Chez les Anciens $\rightarrow$ En la Antigüedad (García Pelayo y Gross y Testas, 1967, artículo chez).

\footnotetext{
${ }^{6}$ En español, las referencias espaciales ligadas al ejercicio de una profesión suscitan la designación del lugar con mayor frecuencia que la alusión al oficio; por ejemplo chez le boulanger se traduce más frecuentemente como en la panadería que como en lo del panadero.
} 
(vii) Chez $\rightarrow$ Ante

(21) II m'a fait promettre de ne pas dire cela à l'audience, ni chez le magistrat instructeur $\rightarrow$ Me hizo prometer que no dińa tal cosa en la audiencia ni ante el juez instructor (Camus, 1957 [1942]: 102; trad. de Bonifac io del Camil, 1949: 84).

(viii) Chez $\rightarrow$ Con

(22) II a étudié chez les Jésuites $\rightarrow$ Ha estudiado en / con los Jesuitas (Cadiot, 1997: 271).

(23) Anne-Marie décida de retoumer vivre chez ses parents $\rightarrow$ Anne-Marie [...] decidió volver a vivir con sus padres (Sartre, 1964: 17; trad. de Manuel Lamana, 1964: 13).

(ix) Chez $\rightarrow$ Entre

(24) Chez les paysans il y a plus de noblesse et de droiture $\rightarrow$ Entre los labradores hay má s hidalguía y rec titud (Bouzet, 1946: 143).

(25) On ne médisait point, chez nous, on constatait, dans l'affliction, les défauts d'un caractère $\rightarrow$ No había maledic encia; entre nosotros se veían, con aflicción, los defectos de carácter (Sartre, 1964: 46; trad. de Manuel Lamana, 1964: 35).

(x) Chez $\rightarrow$ Para

(26) C'est rare chez un enfant de son âge $\rightarrow$ Es raro para un niño de su edad (Cadiot, 1997: 271).

De lo expuesto puede observarse que, dado que el español no presenta isomorfismo preposicional con el relacionante francés, la traducción de chez supone una modula ción de las unida des disponibles en la lengua meta. Más aún, el sentido que la preposición francesa ayuda a construir es necesariamente dependiente de su entomo lingüístico con el cual se encuentra en constante interacción: fruto de negociación entre unida des lingüístic as en contexto, el sentido emerge según perfilamientos cambiantes que iluminan gestálticamente (o dejan en la sombra) ciertas facetas de la escena según la aprehensión particular del interpretante.

Más particulamente, se estudiará aquí la interacción entre el sintagma preposicional y la forma verbal ubicada a la izquierda del SP. Así como, por ejemplo, ciertos verbos dinámicos suscitan no sólo la traducción chez $\rightarrow$ a sino también penf́rasis del tipo aller chez $X \rightarrow$ ir a ver a $X$ en virtud de una inferencia de interacción, se observará que, en el caso que nos ocupa, el componente léxico de un verbo como prendre (tomar), en interacción con la preposición, habilita interpretaciones de tipo funcional, es decir sobre la base no ya de una simple localización espacial sino de una interacción pertinente entre los actantes designados por la esc enific ac ión disc ursiva. 
En efecto, prendre moviliza, desde el gesto físico de asir con la mano, una constelación de imá genes de la aprehensión: llevar / traer consigo, a rrancar, retirar pero también acoger, recibir. El verbo puede así indicar una relación abstracta de apropiación, indicando 'hacer suyo' $y$, entre otros empleos, s'adjoindre une personne (adquirir la compañía de una persona) por ejemplo prendre quelqu'un à son service (tomar a alguien a su servicio) en el sentido de employer (emplear), engager, embaucher (contratar). Tal sentido entrará en especial consonancia con la noción de pertenencia subyacente en el empleo de la preposición francesa chez que evoca un espacio concéntrico vectorizado hacia el ser animado designado por el SP. Por tal motivo, este espacio se concibe, usualmente, como un teritorio propio (Cadiot y Visetti 2001), espacio, por supuesto, sujeto a tensiones.

Precisamente, en el estudio que se presenta a continuación, el análisis de diferentes versiones españolas de la secuencia prendre chez + pronombre da cuenta de la existencia de una diversidad de modalidades de presencia que, latentes en el texto de partida, emergen en cada una de las formulaciones posibles en $L 2$ relevadas en nuestro cuerpo de datos.

\section{Corpus de observables de traducción}

Para este análisis, tomamos seis traducciones de Le Rouge et le Noir. Chronique du XIXe siècle de Stendhal (edición de 1937 del original public ado en 1830). No es ajena a esta elección la existencia de una multiplicidad de versiones (fundamental para nuestro estudio) ni el género litera rio que sitúa personajes y acciones con referencia en el espacio-tiempo.

Se relevaron empleos preposic ionales en:

(i) cuatro traducciones españolas, a saber

- Rojo y negro, edición de 1963, con traducción de M. de Ortiz, publicada en Barcelona por Ed itorial Maucci;

- Rojo y negro, edición de 1968, con traducción de Consuelo Bergés para Aguilar S.A. (España), public ada en Argentina por el Centro Editor de América Latina;

- Rojo y negro, edic ión de 1982, con traducción de Emma Calatayud para Ediciones Orbis S.A. y Rodrigo, Barcells y Alta miba Proyectos Ed itoriales S.A. (España), publicada en Argentina por Hispa méric a Edic iones Argentina S.A.;

- Rojo y negro, edición de 2001, con traducción de Carlos Pujol y Tania de Bemúdez-Cañete publicada por Editorial Planeta (España) en edición especial para La Nación (diario de Argentina).

(ii) dos traduc ciones a rgentinas:

- Lo rojo y lo negro. Crónica de 1830, edición de 2009, con traducción de Patricia Nirimberk y Manuel Lamana, para Ediciones Corregidor, Buenos Aires; 
- Rojo y negro, edición de 2010, con traducción de Belén Jáuregui para Gradifco SRL, Buenos Aires ${ }^{7}$.

Nuestro estudio se centra en la primera parte de la novela (pp. 3-244) que transc urre en el pueblo de Verrères. El relato comienza con una descripción general de la región que, cinematográficamente, enfoca con mayor detalle el pueblo, la calle y finalmente, como en un efecto óptic o de zoom, la casa del alcalde, el señor de Rênal. La morada del alcalde es mucho más que un escenario: es precisamente en ella donde se desarrollará la acción de esta primera parte de la novela cuyas consecuencias se extenderán en la segunda y deteminarán el desenlace final. En efecto, contratado por el señor de Rênal como preceptor para sus hijos, el joven Julien Sorel se instalará en el domicilio de este, conocerá a la señora de Rênal y ambos se enamorarán. El ingreso del preceptor en la casa y, más suún, en el seno de la familia (y particularmente del matrimonio) alterará el delicado equilibrio inicial. Altamente simbólico -habitado y que a la nos vez habita ${ }^{8}$ (Bachelard, 1967 [1957]: 19) -, el espacio doméstico se encuentra entroncado con el ser mismo de los personajes, con la voz del narrador, con el punto de vista del enunciador, espacio con resonancia particular en la subjetividad del receptor.

Desde esta perspectiva, concentramos nuestra atención en los casos en los que el sintagma preposicional chez + pronombre remite a la casa de la familia de Rênal, casa que, en la trama narrativa, deviene un campo de fuerzas en el que se tensionan habitación, ocupación, pertenencia y posesión. Estas tensiones del espacio doméstico (el chez-soi) generan un halo de ambigüedad que envuelve los empleos de la preposición. Como se observará en el apartado siguiente, cada traducción ilumina o relega a la penumbra algunos de estos aspectos según la sensibilidad, la a prehensión y la elaboración del tra ductor.

\section{Análisis de casos}

Se relevaron quince alusiones a la casa del señor de Rênal en coocurrencia con diversos verbos. Por una cuestión de extensión, abordaremos, sin más detalle, dos fragmentos en los que la preposición coocurre con el verbo prendre, extractos que revelan los componentes de pertenencia y dominio que subyacen en la evocación del espacio vectorizado porla preposición chez.

Estos fragmentos, separados por más de 150 páginas, marcan dos momentos clave en el desarrollo de la acción y, en el personaje del alcalde, dos estados de ánimo diametralmente opuestos. En el primero de ellos, seguro de sí, el señor de Rênal expresa (discurso directo) su voluntad de tomar a Julián Sorel como preceptor para sus hijos, decisión que, estima, le facilitará la vida. En cambio en el segundo, según lo relata el narrador omnisciente, el marido engañado, al tanto de la

\footnotetext{
${ }^{7}$ No se abordarán en este a nálisis cuestiones particula res de variación lingüística o de contra ste entre el español peninsular y el hispanoamericano. Las opciones de traducción de la secuencia prendre chez + pronombre no presentan mayores peculiaridades a nivel diatópico y resultan usuales en ambos casos.

8 Las imágenes de la casa, afima Bachelard (1967 [1957]), se mueven en dos sentidos: están en nosotros aś como nosotros estamos en ellas ("Les images de la maison marchent dans les deux sens: elles sont en nous autant que nous sommes en elles."(Bachelard, 1957 : 19)
} 
infidelidad de su esposa, lamenta amargamente haber tomado aquella decisión: la segunda ocurrencia aparece así como el amargo eco de la primera.

Pese a tratarse de la misma expresión (prendre chez + pronombre), la aprehensión y puesta en palabras propuesta por cada traductor exhibe variantes dentro de un continuum entre evocación de una interacción pertinente y la escenific ación de la intrusión en el espacio privado.

\section{1. La evocación de una interacción pertinente}

Observemos el primer fragmento y sus seis versiones en español.

En (27), el señor de Rênal se encuentra en el jardín junto a su esposa. Uno de sus hijos acaba de cometer una travesura y este incidente precipita el comentario del protagonista:

(27) - Je veux absolument prendre chez moi Sorel, le fils du scieur de planches, dit M. de Rênal ; il surveillera les enfants, qui commencent à devenir trop diables pour nous. C'est un jeune prêtre, ou autant vaut, bon latiniste, et qui fera faire des progrès aux enfants; car il a un caractère ferme, dit le curé. Je lui donnerai 300 francs et la noumiture (Stendhal, Le Rouge et le Noir. Chronique du XIXe siècle, ed. 1937, p. 13).

De marcada modalidad volitiva (je veux), la intervención del alcalde deja traslucir una fuerte personalidad: nótese el empleo de la primera persona, particulamente para referirse al hogar del matrimonio (chez moi y no chez nous mientras habla con su esposa) y el ca rácter categórico de su decisión ma rcado por el adverbio absolument. Su discurso, que esboza un proyecto de contratación, antic ipa la s condic iones laborales de J ulien Sorel a saber, sus func iones: il surveillera les enfants, fera faire des progrès aux enfants (cuidará de los niños y los hará progresar en sus estudios); su perfil: jeune prêtre, bon latiniste, caractère ferme (joven sacerdote, buen en latinista, de carácter fime); su remuneración: 300 francs et la nouriture (300 francosy la comida).

En este contexto, la expresión prendre chez moi puede interpretarse no sólo como la admisión en el espacio de su propia casa (puesto que las tareas del preceptor se desarrollarán en ese ámbito), sino también como el inicio de una relación laboral. En el primer caso, se focaliza el empleo de la preposición chez que vectoriza el espacio hacia el temitorio propio del alcalde; en el segundo, el verbo prendre se encuentra en consonancia con employer, engager, embaucher y sugiere una relación profesional.

Veremos que cada versión española del texto original ilumina o relega a la penumbra algunos de estos aspectos según la sensibilidad, la aprehensión y la elaboración del traduc tor.

En la refomulación de prendre chez moi pueden identificarse dos tendencias interpretativas mayores: la introducción en el espacio doméstico propio y la evocación de una relación profesional. Observemos (28) y (29):

(28) -Estoy completamente decidido a traer a mi casa a Sorel, el hijo del asemador de tablas-manifestó monsieur de Rênal-; se cuidará de los niños, que comienzan a ser demasiado malos para nosotros. Es un joven 
sacerdote, o como si lo fuera; buen latinista, y hará adelantar a los niños, pues, según dice el cura, tiene mucho carác ter. Le da ré trescientosfrancos y la comida (Stendhal, Rojo y negro, ed. 1968, trad. de Consuelo Bergés, p. 17).

(29) Estoy resuelto a traer a nuestra casa al hijo del aserrador Sorel -dijo el alcalde-. Tomará a su cargo la vigilancia de nuestros hijos, que comienzan a hacerse demasiado diablillos. Es un medio cura, excelente latinista, que cuidará de su instrucción y les obligará a aprender, pues si no me ha engañado el párroco, tiene un carácter firme. Le daré trescientos francos y mesa (Stend hal, Rojo y negro, ed. 1963, trad. de M. de Ortiz, p. 23).

En estas dos versiones, las alusiones a la casa se encuentran más o menos moduladas por la figura del propietario: el verbo traer, evoca el desplazamiento hacia un campo de fuerzas simbólico en cuyo centro se encuentra la figura del señor de Rênal. Su presencia es altamente pregnante en traer a mi casa (28), traslación directa de chez moi, y atenuada en (29), por la alusión a un espacio compartido (a nuestra casa), es decir al hogar común, en el contexto de una conversación entre marido y mujer. En ambos casos podría decirse que estas formulaciones, en primera lectura partic ulamente cercanas a la expresión del texto original y fieles a la etimología de chez, prefiguran de algún modo el devenir dramático de la historia que comienza con la introducc cón de Julien Sorel en la casa del señor de Rênal.

En cambio, en (30)-(33), a parece una interpretación de carácter más abstracto, orientada hacia la relación contractual:

(30) -Estoy empeñado en tomara mi servicio a Sorel, el hijo del a semador dijo el señor de Rênal-. Podrá vigilar a los niños, que ya son demasiado traviesos para nosotros. Es un joven sacerdote o algo parecido, buen latinista y que hará progresar en sus estudios a nuestros hijos. Tiene un carácter firme, según me dijo el cura. Le daré 300 francos y la comida (Stendhal, Rojo y negro, ed. 1982, trad. de Emma Cala tayud, p. 18).

(31) -Estoy empeñado en tomara mi semicio a Sorel, el hijo del a serrador dijo el señor de Rênal-. Podrá vigilar a los niños, que ya son demasiado traviesos para nosotros. Es un joven sacerdote o algo parecido, domina el latín y hará progresar a nuestros hijos en sus estudios. Tiene un carácter fime, según me dijo el cura. Le daré 300 francos más alimentación (Stendhal, Rojo y negro, ed. 2010, trad. de Belén Jáuregui, p. 25).

(32) -Estoy decidido a empleara Sorel, el hijo del a semador-dijo el señor de Rênal-; vigilará a los niños que comienzan a ponerse demasiado diablos para nosotros. Es un sacerd ote joven o poco menos, buen latinista, y hará progresar a los niños, pues, según dice el cura, tiene un carácter firme. Le daré trescientos francos y la comida (Stendhal, Lo rojo y lo negro. Crónica de 1830, ed. 2009, trad. de Patricia Nirimberk y Manuel La mana, p. 18). 
(33) -Estoy tota Imente decidido a contratar a Sorel, el hijo del asemador dijo el señor de Rênal-; él se encarga rá de vigilara los niños, que empiezan a ser demasiado traviesos para nosotros. Es un joven sacerdote, o como si lo fuera; sabe mucho latín, y hará que los niños progresen; porque tiene un carácter fime, dijo el cura. Le daré trescientos francos y la comida (Stendhal, Rojo y negro, ed. 2001, trad. de Carlos Pujol y Tania de Bermúdez-Cañete, p. 17).

Esta interpretación funcional, es dec ir en términos relacionales, pa rece invisibilizar el espacio habitado: no se registra alusión a la casa aunque se trate del futuro lugar del trabajo del preceptor-lugar que debe ser inferido por el lector en base a su conocimiento del mundo-. En efecto, las cuatro versiones ut supra privilegian la interpretación profesional del verbo prendre (tomar) que no aparece ya bajo la forma (más física) del deíc tic o traer sino que es objeto de una lectura 'profesional' con una variada paleta de matices. Así, en (30) y (31), se percibe una fuerte expresión de asimetría con particular relieve de la figura dominante del alcalde: como forma abstracta de apropiación, tomar a mi senvicio (con una saliencia particular del posesivo singular) evoca la singularidad de chez moi y magnifica la figura del señor de Rênal. En las dos últimas versiones, se observan expresiones más neutras como emplear (32) $y$, particulamente, contratar (33) que, connotativamente, alude a una relación centrada en el trabajo más que en el servicio.

Así, la multiplicidad de fomulaciones en español de la relación instanciada en francés por la secuencia prendre chez moi permite apreciar la diversidad de aprehensiones y de escenificaciones que surgen en la instancia subjetiva de traducción. Como se verá en el a partado siguiente, la misma construcción da lugar, en otro contexto, a nuevos matic es en las versiones en español.

\section{2. La escenificación de la intrusión en un espacio privado}

En este fragmento, lejos ya del discurso directo del alcalde expresado en (27) con resolución y autoridad, el narrador omnisciente describe la pesadumbre del señor de Rênal como marido que se sabe traicionado: la decisión de tomar un preceptor en su casa ha resultado fatal para su matrimonio y su hogar.

(34) M. de Rênal, maudissant mille fois le jour où il avait eu la fatale idée de prendre un précepteur chez lui, oublia la lettre anonyme (Stendhal, Le Rouge et le Noir. Chronique du XIXe siècle, éd. 1937, p. 170).

Cabe resaltar que, si en (27), la fomulación del señor de Rênal designaba como argumento a Sorel, le fils du scieur de planches (Sorel, el hijo del aserrador), en (34), se trata de una evocación mucho más genérica, un précepteur (un preceptor), designación que, en principio, alude a la función profesional del actante. Una sola versión, (35), evoca la relación profesional sin evocar el espacio doméstico: tomar un preceptor para sus hijos.

(35) El señor Rênal, atento a maldecir del día que tuvo la fatal idea de tomar un preceptor para sus hijos, terminó por dar al olvido el a nónimo (Stend hal, Rojo y negro, ed. 1963, trad. de M. de Ortiz, p. 203). 
Puede observarse que, en esta traducción, no se hace referencia explícita a la casa del alcalde sino a la contratación de un maestro para los niños (la indicación espacial siendo, aquí, inferida del contexto). A tal respecto, nótese que, para (27), cuatro versiones ofrecían una interpretación de prendre chez + pronombre en términos profesionales omitiendo la referencia a la morada del señor de Rênal. La proporción parece invertirse para la traducción de (34).

Pese a la coocurrencia del lexema précepteur, que podría dingir las inferencias hacia una lectura más 'técnica', no aparecen, en las cinco interpreta ciones ut infra, verbos neutros como emplear o contratar. En todas estas versiones, emerge la imagen de la intromisión de un extraño en el delicado equilibrio del ámbito familiar con diferentes grados de intensidad: tomar un preceptor en su casa (36), hacer entrar en su casa un preceptor (37), meter un preceptor en su casa (38), meter a un preceptoren su casa $(39,40)$.

(36) El señor de Rênal, maldiciendo mil veces el día en que tuvo la fatal ocurrencia de tomar un preceptor en su casa, olvidó la carta anónima (Stendhal, Lo rojo y lo negro. Crónica de 1830, ed. 2009, trad. de Patricia Nirimberk y Manuel Lamana, p. 184).

(37) El señor de Rênal, maldiciendo mil veces el día en que había tenido la fatal idea de hacer entrar en su casa un preceptor, olvidó la carta a nónima (Stendhal, Rojo y negro, ed. 2001, trad. de Carlos Pujol y Tania de Bermúd ez-Cañete, p. 174).

(38) Monsieur de Rênal, maldiciendo mil veces la hora en que se le ocumí la fatal idea de meter un preceptor en su casa, olvidó el a nónimo (Stendhal, Rojo y negro, ed. 1968, trad. de Consuelo Bergés, p. 201).

(39) El señor de Rênal, maldiciendo mil veces el día en que tuvo la fatal ocurrencia de meter a un preceptor en su casa, olvidó la carta anónima (Stend hal, Rojo y negro, ed. 1982, trad. de Emma Cala tayud, p. 172).

(40) El señor de Rênal, maldiciendo mil veces el día en que tuvo la fatal ocurrencia de meter a un preceptor en su casa, olvidó la carta anónima (Stendhal, Rojo y negro, ed. 2010, trad. de Belén Jáuregui, p. 176).

Es interesante comparar las versiones suscitadas por (27) y (34). Como se señaló anteriomente, en (27), el verbo prendre motivaba diferentes formulaciones en base a dos lecturas posibles: una interpreta ción abstracta (tomar a mi senvicio, emplear, contratar) y una más ligada a la dimensión física, traer, deíc tic o de desplazamiento con polaridad final orientado desde la perspectiva del hablante. Si bien esta doble interpretación se mantiene en las versiones de (34) con una lectura abstracta (tomar un preceptor para sus hijos) y una lectura más espacial, cabe resaltar, en algunos casos, la fuerza partic ular de esta última.

Diversas fomulaciones evocan el espacio doméstico. En (36), el traductor equilibra ambas interpretaciones de prendre chez + pronombre sumando relación contractual (tomar un preceptor) y zona de interacción (en su casa). En los 
fragmentos restantes, la traducción al español del verbo prendre y su SP no da lugar al empleo del verbo traer, como en (28) y (29), sino a una escenificación de la intrusión en el espacio propio: en (37), la mediación traductiva ilumina particulamente no ya el desplazamiento polarizado sino el traspaso de los límites del espacio doméstico (hacer entrar en su casa). El verbo entrar, sugiere especialmente la introducción de un elemento extraño en un espacio interior (íntimo) en el marco de una dialéctica entre el adentro y el afuera. Tal efecto se potencia en (39)-(40), por el empleo del verbo causativo meter de mayor efecto intrusivo dentro del espacio vectorizado hacia el señor de Rênal evocado por la preposición chez. Contribuye a tal efecto de sentido la selección preposicional en español: en (28) y (29), el verbo traer se construye con la preposic ión a, rela cionante direccional que señala el témino de una trayectoria sin descripción particular del espacio, mientras que, en (37)-(40), los verbos entrar y meter coocurren con la preposic ión en, que sugiere interionidad.

Asimismo, cabe notar, en (39) y (40), el efecto de singularización del actante generado por la introducción de la preposición a (meter a un preceptor), en contraste con la despersonalización de la construcción directa (Pottier, Darbord y Charaudeau, 1994: 251) empleada en (36)-(38). Tal singularización acentúa aún más la imagen de imupción en el temitorio propio. La traducción de prendre chez lui, como acción vectorizada hacia el espacio íntimo del alcalde, recupera en este contexto toda su dimensión temitorial.

Al cabo de esta primera aproximación al comportamiento semánticopragmático de la secuencia prendre chez + pronombre según las diferentesfacetas iluminadas por cada una de las versiones en español, esbozamos las conclusiones de nuestro estudio.

\section{Conclusiones}

Partiendo de una concepción holística, gestáltica y fenomenológica de la construcción del sentido, nuestro estudio se basó en un enfoque enunciativo de la traducción: cada una de las reescrituras en $L 2$, según la modalidad de presencia generada en la consciencia perceptiva del traductor, ofreció una perspectiva partic ularde la escena evocada en el original.

Así, la descripción del comportamiento semántico-pragmático de la secuencia prendre chez + pronombre se enriqueció con las escenificaciones altemativas sugeridas por cada versión. Se detectaron dos tendencias predomina ntes:

(i) la evocación de una interacción pertinente entre la entidad a situar, en este caso Julien Sorel, y la entidad de referencia, el temitorio propio del señor de Rênal. La identificación entre el espacio designado y su propietario (visible en francés por la referencia al actante animado en el sintagma encabezado por chez) sin descripción espacial particular habilita transposiciones en témminos de interacción personal como tomara mi servic io, emplear, contratar. Tales reformula ciones surgen principalmente en un contexto neutro donde no se percibe aún tensión en el campo de fuerzas del espacio propio.

(ii) la escenific ación de la intrusión en el espacio privado del señor de Rênal. En un contexto de mayor intensidad emocional, la dimensión teritorial que subyace en 
el semantismo de la preposición francesa aparece iluminada particulamente por la elección de verbos de interioniza ción (hacer entrar, meter) que resaltan el traspaso del perímetro del espacio personal.

Se desprende del análisis de casos que las modalidades de presencia emergentes de cada versión en español dan cuenta de la dimensión enunciativa de la traducción como escenificación construida por el traductor en su coconstrucción del texto en $L 2$.

\section{Bibliografía}

ADEKPATE, A. (2012) : "L'expression des valeurs d'emploi de chez dans les langues africaines: l'exemple du kroubou». Revue électronique intemationale de sciences du langage Sudlangues, 17, pp. 75-90.

BACHELARD, G. (1967 [1957]) : La poétique de l'espace. Paris: PUF.

BERMAN, A. (1985) : La traduction et la lettre ou l'auberge du lointa in. A. BERMAN. (ed.) : Les tours de Babel. Mauvezin : Trans-Europ-Repress, pp. 33-150.

Bou正, J . (1946) : Gramma ire espagnole. Paris : Belin.

CADIOT, P. (1997) : Les prépositions abstraites en fra nçais. Paris : Arma nd Colin.

CADIOT, P. et Y.-M. VISETI (2001) : Pour une théorie des formes sémantiques. Profils, motifs, thèmes. Paris : PUF.

ChaRAUDEAU, P. (1992) : Grammaire du sens et de l'expression. Paris: Hachette Livre.

CONDAMINES, A. (2000) : «Chez dans un corpus de sciences naturelles: un marqueur de relation méronymique ? ». Cahiers de Lexic ologie, 77, pp. 165-187.

DAUZAT, A.; J . DUBoIs et H. MITTERRAND (1964) : Nouveau Dictionnaire Étymologique et Historique. Paris : La rousse.

FUCHS, C. (1982) : La paraphrase. Paris : PUF.

GARCIA-PELAYO Y GROSS, R. et J. TESTAS (1967): Dictionnaire modeme françaisespagnol, espagnol-français. Paris : La rousse.

GougenHeIM, G . (1972 [1952]) : Les Mots Français dans l'histoire et dans la vie. Tome I. Paris: A. et J. Pic ard.

LADMIRAL, J .-R. (1979) : Tra duire: théorèmes pour la traduction. Paris : Payot.

LEEMAN, D. (1989) : «Est-ce qu'on peut aller au coiffeur ». Lingvistic ae Investigationes XIII/ 2, pp. 399-404.

LE SCOUARNEC, R.-P. (2007) : «Habiter, demeurer, a ppartenir ». Collection du Cirp, I, pp. 79-114.

MILNER, J .-C . (1989) : Introduction à une science du langage. Paris : Éditions du Seuil.

Potmer, B., B. DARBORD et P. ChARAUdeAU (1994): Grammaire explicative de l'espagnol. Paris: Nathan.

Real Academia Española y Asociación de Academias de la Lengua Española (2009). Nueva gramática de la lengua española. Disponible en www.rae.es. Consulta do el 30/06/2014.

SCHNEDEC KER, C. (2007) : «Un ciel... gris de chez gris... » : de la construction X de chez $X$ à Adj de chez Adj : du locatif à l'intensif ». Travaux de linguistique, 55/2, pp. 61-73. 
Trésor de la langue française informatisé. Disponible en: http://atilf.atilf.fr/tlfi.htm. Consultado el 22/09/2011.

VICTORRI, B. et C. FUCHS (1996) : La polysémie. Construction dynamique du sens. Paris : Hermès.

Corpus primario :

BEAUVOIR, S. de (1967) : La femme rompue. L'âge de discrétion. Monologue. Paris : Gallimard.

BEAUVOIR, S. de (1974): La mujer rota. La edad de la discreción. Monólogo. D. SIERRA y N. SÁNCHEZ (trads.). Buenos Aires: Ed itorial Sudameric ana.

CAMUS, A. (1957 [1942]) : L'étranger. Paris: Gallimard.

CAMUS, A. (1949): El extra njero. B. del CARRIL (trad). Buenos Aires: Emecé Editores S.A. SARTRE, J.-P. (1964) : Les mots. Paris: Gallimard.

SARTRE, J.-P. (1964): Las Palabras. M. LAMANA (trad.). Buenos Aires: Editorial Losada.

STENDHAL (1937 [1830]) : Le Rouge et le Noir. Chronique du XIXe siècle. Paris : Éditions de Cluny.

STENDHAL (1963): Rojo y negro. M. de ORTIZ(trad.). Barcelona: Editorial Maucci.

STENDHAL (1968): Rojo y negro. C. BERGÉS (trad.) para Aguilar S.A. (España). Publicado en Argentina por el Centro Editor de Améric a Latina.

STENDHAL (1982): Rojo y negro. E. CALATAYUD (trad.) para Ediciones Orbis S.A. y Rodrigo, Barcells y Altamiba Proyectos Editoriales S.A. (España). Public ado en Argentina por Hispaméric a Edic iones Argentina S.A.

STENDHAL (2001): Rojo y negro. C. PUJ OL y T. de BERMÚdEZ-CAÑETE (trads.). Barc elona: Editorial Planeta. Edición especial para La Nación.

STENDHAL (2009): Lo rojo y lo negro. Crónica de 1830. P. NIRIMBERK y M. LAMANA (tra ds.). Buenos Aires: Edic iones Corregidor.

STENDHAL (2010). Rojo y negro. B. JÁUREG Ui (tra d.). Buenos Aires: Gradifco SRL 